\title{
La formación cívica y ética en la escuela: entre la instrucción y la formación
}

\author{
Ethics and Civic Education in the School: \\ Between Instruction and Formation
}

Lucía Elena Rodríguez Mc Keon ${ }^{1}$

\author{
Resumen
}

Los resultados de investigación que se presentan en este trabajo se refieren al análisis de los procesos de significación que realizan los docentes de educación primaria con respecto al Programa Integral de Formación Cívica y Ética en el ámbito de su práctica. Dicha propuesta, impulsada a partir de 2008, introduce un carácter democrático en la formación que se convierte en anatema del enfoque constitucionalista y patriota que ha prevalecido en el ámbito educativo. A través de una indagación intensiva de tipo cualitativo, se realizó un estudio de caso en una escuela primaria ubicada en la Ciudad de México. Con el apoyo de la entrevista a profundidad y la observación a diez docentes de los grados de primero a sexto de primaria, reconstruimos la valoración que los maestros le otorgan al nuevo programa, en términos de su significatividad y transferencia en el ámbito de su práctica. La tesis de discusión sugiere que la apropiación del nuevo enfoque de formación cívica y ética se ve obstaculizada por la presencia de un modo de gestionar el saber pedagógico que reproduce una cultura de la instrucción, en detrimento del impulso de procesos de formación democrática, centrados en la deliberación y la comprensión crítica.

\section{Palabras clave}

Formación cívica y ética, deliberación, comprensión crítica, inculcación, deliberación.

\section{Abstract}

The research results presented in this paper refer to the analysis of the processes of meaning made by primary school teachers related to the Integral Program of Ethics and Civic Education within the scope of their practice. This proposal, led from 2008, introduces a democratic character into education that becomes anathema to the constitutional and patriotic approach that has prevailed in education. Through an intensive qualitative investigation a case study was conducted in a primary school in Mexico City. Supported by in-depth interviews and observation of 10 teachers of first to sixth grades, we reconstruct the assessment given by teachers to the new program, in terms of its significance and transfer within the scope of their practice. The thesis for discussion suggests that appropriation of the new civic and ethical education approach is hindered by the presence of a way to manage the pedagogical knowledge that reproduces a culture of instruction at the expense of democratic formation processes that are focused on deliberation and critical understanding.

\section{Keywords}

Civic and ethical education, deliberation, critical understanding, inculcation and deliberation.

\section{Artículo recibido el 27 de octubre de 2014 - aprobado el 11 de noviembre de 2014}


Los resultados de investigación que se presentan en este trabajo se refieren al análisis de los procesos de significación que realizan los docentes de educación primaria, con respecto a la nueva propuesta de formación cívica y ética puesta en práctica a partir del 2008 en el ámbito de su práctica. Partiendo de la consideración de que los procesos de instrumentación de las reformas se realizan en un campo signado por múltiples tensiones, cuando se busca afectar la relación saber-poder que sostiene el modo tradicional de ejercer la práctica educativa en el campo, en el estudio realizado, nos interesó conocer lo que está sucediendo en las instituciones educativas, en términos de sus procesos de apropiación y las repercusiones en la reconfiguración de la identidad docente.

En este artículo en particular, se comparten los resultados obtenidos en torno a una de las líneas de indagación construidas en referencia a la dificultad identificada para incorporar en la práctica el nuevo enfoque en la formación cívica y ética, cuando existen resistencias para modificar el modo como se ha gestionado tradicionalmente el saber pedagógico en la escuela.

A partir de la reconstrucción realizada, identificamos que la apropiación de dichas estrategias se ve obstaculizada por la presencia de una cultura de la instrucción, que niega la posibilidad de problematizar la realidad que viven niños y niñas, asumiendo que, a través de dicha reflexión, es posible acercarnos al diagnóstico acerca de los significados que maestros y maestras construyen en torno a la pertinencia del nuevo modelo de formación cívica y ética.

Al impedir el desarrollo de la comprensión crítica, se promueve la preservación de las prácticas de la inculcación y el adoctrinamiento, como estrategias que limitan la posibilidad de contribuir al desarrollo del juicio crítico, para pensar su realidad y hacerse cargo de su transformación como uno de los propósitos fundamentales del nuevo programa de estudio. La permanencia de dichos modos de gestionar pedagógicamente los saberes en la formación condiciona fuertemente la posibilidad de modificar las prácticas en el campo de la cívica y ética, cuando lo que evidencian es la preservación de ciertas lógicas de razonamiento ${ }^{2}$ que están vigentes en el discurso pedagógico.

\section{Metodología}

A partir de un acercamiento de tipo cualitativo, se realizó un estudio de caso en una escuela primaria ubicada en la Ciudad de México. Se seleccionaron diez maestros, cinco mujeres y cinco hombres y la directora de la escuela, a quienes se aplicaron entrevistas y se realizó un grupo focal, además de sesiones de observación de sus prácticas en clase. Debido al carácter de la investigación, el procedimiento de selección de los informantes se concibió de modo abierto, con un carácter dinámico y secuencial, capaz de satisfacer las necesidades que fueron surgiendo en el proceso de indagación mismo (Rodríguez, Gil y García, 1999). Si bien en un inicio dicha estrategia privilegiaba a los maestros con más experiencia, en la medida en que se avanzó en la fase de trabajo de campo, decidimos ampliar el criterio hacia los maestros de reciente incorporación en el servicio educativo a fin de contrastar su experiencia. Así se eligieron docentes de ambos sexos, que mostraban un manejo distinto de las normas escolares y utilizaban diversos modos de intervenir, además de que poseían una antigüedad distinta. En todos los casos, el proceso de selección tomó en cuenta la disposición a participar y la capacidad para expresar claramente sus ideas y para la reflexión.

Las entrevistas se aplicaron a docentes de los grados que van de primero a sexto. Esta se centró en la conversación, aunque partió de una lista de temas orientados hacia el logro de un propósito explícito. A través de la verbalización asociada libremente, instalaron los aspectos que, desde su perspectiva, resultaron más relevantes en relación con la temática tratada, y también se incentivó que se hablara

2 Tal como plantea Fuentes Amaya (2004), “pensar desde una lógica discursiva de razonamiento supone organizar estratégicamente el pensamiento desde una consideración básica: que toda práctica social, por ende también la educativa, puede inteligirse como proceso de significación en el cual es posible distinguir sistemas significantes construidos políticamente en contextos históricos particulares, que suponen fijaciones de sentido contingentes y por tanto abiertas, precarias y temporales" (p. 164). 
sobre sus experiencias y que se describiera e hiciera relatos (Rodríguez, Gil y García, 1999; Taylor y Bogdan, 1987). El grupo de discusión resultó de suma utilidad para profundizar en las visiones que los docentes tienen en torno a la formación cívica, así como para identificar las contradicciones existentes entre ellos. Se recogió información también, mediante la observación participante, del desarrollo de las prácticas e interacciones cotidianas en el aula y la escuela. Con base en la información recogida, se pudieron identificar determinadas maneras de hacer, de habitar y de hablar propias de cada tipo de sujeto, que se distinguen entre las de los demás, tal como lo plantea Michel de Certau (1996). En este sentido, el análisis de prácticas e interacciones permitió reconocer cómo se despliegan modos y estrategias de relación con el programa entre los docentes, indisolublemente ligados a la forma como lo asumen en sus prácticas educativas cotidianas. Esta tarea se realizó apoyada en el diario de campo. Finalmente, y para contar con la información necesaria, se recolectaron documentos, materiales y artefactos producidos en la experiencia y que brindaron información acerca de las estrategias seguidas en la puesta en práctica del programa (materiales y libros de texto). De igual manera, se recolectaron evidencias en torno a la forma de articulación del programa con los procesos de enseñanza y de aprendizaje de otras asignaturas.

Para fines de análisis, se organizaron y reconstruyeron los datos con respecto a la significatividad del programa, sus ámbitos y dimensiones de incidencia y su articulación con las prácticas cotidianas. En los procedimientos de categorización de la información obtenida, se hizo énfasis en la identificación de las tensiones que aparecen en los procesos de significación de los docentes, suponiendo que ello nos permitiría ubicar algunos de los factores que explican las condiciones de desarrollo del nuevo programa. Lo que interesó fue identificar los cambios que produce, entendiendo que no son simples mecanismos de sustitución parcial y tampoco transformaciones totales (de las cuales habría que desconfiar), sino transiciones que devienen en el ámbito educativo, al darse nuevas condiciones para el desarrollo de las prácticas de la formación cívica y ética.

\section{Algunas notas sobre el Programa Integral de formación cívica y ética}

Si bien desde 1993 se inicia en México un proceso de reconceptualización en la formación cívica y ética, es en 2007 cuando se replantean de manera significativa las finalidades y estrategias que habrán de orientar la tarea de formar a los futuros ciudadanos desde la escuela.

En contraposición con la perspectiva articulada a la conformación de una ciudadanía nacional ${ }^{3}$, a través del enfoque de tipo constitucionalista ${ }^{4}$ que hasta ese momento había sido predominante en el campo, el Programa Integral de Formación Cívica y Ética (PIFCYE) plantea un giro paradigmático al destacar el carácter democrático que debe adquirir dicha formación:

La formación cívica y ética en la escuela es un proceso basado en el trabajo y la convivencia escolar, donde niñas y niños tienen la oportunidad de vivir y reconocer la importancia de principios y valores que contribuyen a la convivencia democrática y a su desarrollo pleno como personas e integrantes de una sociedad. [...] promueve la capacidad de los alumnos para formular juicios éticos sobre acciones y situaciones en las que requieren tomar decisiones, deliberar y elegir entre opciones que, en ocasiones, pueden ser opuestas. En este razonamiento ético juegan un papel fundamental los principios y valores que la humanidad ha forjado: respeto a la dignidad humana, justicia, libertad, igualdad, solidaridad, responsabilidad, tolerancia, honestidad, aprecio y respeto de la diversidad cultural y natural (SEBYN, 2008, p. 213).

3 En esta perspectiva de formación, lo que interesa es la inculcación de valores comunes asociados a la nacionalidad a través del conocimiento objetivo de la historia patria, de la geografía y de las instituciones políticas como fuente de cohesión social y de generación de patriotismo.

4 Para Gómez (1998, p. 61), el enfoque constitucionalista en la educación cívica se refiere al carácter de heteronomía moral que adquiere el aprendizaje de las leyes, cuando estas se asumen como una entidad externa cuya fuente de legitimación última aparece oculta y disfrazada. Esta manera de enfocar la enseñanza de los derechos, no está centrada en el ethos democrático mediante el cual los ciudadanos son, simultáneamente, los productores y destinatarios de la ley. 
Con el PIFCYE se realiza una ruptura significativa con la tradición doctrinaria del nacionalismo cultural de la Revolución mexicana, que buscaba la conformación de un patriota comprometido con los símbolos patrios, como lo señala Guevara (2006). Al abrir cauces hacia la comprensión de la educación cívica desde una posición de sujeto, fundamentada en la libertad personal, el enfoque pedagógico que sustenta a dicho plan y programas, parte de la premisa de que los alumnos desarrollen la capacidad de juicio crítico, que movilicen sus conocimientos dentro y fuera de la escuela, que lo aprendido trascienda la dimensión escolar, que repercuta en su actuar en la vida cotidiana y que sean capaces de resolver los problemas que se les presenten con acierto y responsabilidad. Todo ello con la finalidad de favorecer el mejor desarrollo de la reflexión ética desde la vertiente personal y social y la capacidad para identificar y analizar condiciones favorables para el desarrollo humano en sociedades complejas.

El programa se orienta hacia el desarrollo de ocho competencias cívicas y éticas, a saber: conocimiento y cuidado de sí mismo, autorregulación y ejercicio responsable de la libertad, respeto y aprecio de la diversidad, sentido de pertenencia a la comunidad, la nación y la humanidad, manejo y resolución de conflictos, participación social y política, apego a la legalidad y sentido de justicia y comprensión y aprecio por la democracia.

Al dejar de ser asumidos los contenidos educativos como saberes transmisibles por adquisición, se releva la necesidad de privilegiar el desarrollo de un tipo de estrategias formativas que, a diferencia de la inculcación y el adoctrinamiento, se orientarán a la creación de situaciones dialógicas que permitan que los estudiantes puedan problematizar y normar su conducta tanto en los aspectos personales como sociales, resaltando que lo fundamental es la dimensión del aprendizaje en los sujetos. Es así que se pretende favorecer que las niñas y los niños adquieran las herramientas necesarias para analizar críticamente su contexto, así como que desarrollen capacidades para conocer, ejercer y defender sus derechos, para participar de forma activa en los colectivos en los que se desenvuelven y para emitir juicios y asumir posturas argumentadas ante asuntos públicos (SEBYN, 2008, p. 215).

Así, apoyados en Bernard (2006), podemos decir que, mientras las propuestas anteriores se reducían a ser un dispositivo de enseñanza centrado en la adquisición de conocimientos, el nuevo programa se plantea como un dispositivo de formación que, a través de múltiples recursos y planos, se propone influir de manera intencional en el ámbito práctico moral, reconociendo la importancia del clima de relaciones que se construye en el aula y la escuela, como espacios fundamentales por los que transcurre dicha formación.

\section{La gestión pedagógica del saber práctico en la formación cívico y ética: un reto en la práctica docente}

Entendemos a la formación en el campo de la cívica y ética como aquel proceso de aprendizaje práctico-moral que favorece la conformación de disposiciones en los sujetos para actuar, relacionarse y participar con los otros, consigo mismo y el mundo, propiciando modos de adscripción específicos en relación con el orden social y político, a través de la interiorización de valores, símbolos, actitudes y procedimientos, de larga duración a través de los cuales se propicia que el sujeto se reconozca a sí mismo como ciudadano, propiciando determinados comportamientos relacionados con dicho ejercicio, en función de normas, valores, actitudes, expectativas, modos de conducta, pensamientos y emociones.

Asumida como construcción del sujeto por sí y para sí desde una doble dimensión socio-moral y existencial que se construye con los otros, en el mundo social y en el cuidado de sí, en el sentido planteado por Yurén $(2005$, p. 24), la formación cívica y ética ha de hacernos capaces de lenguaje, de acción, de interacción con los otros y de relación consigo mismos cuando se asume desde una posición de sujeto.

Desde esta perspectiva, los procesos de formación cívica y ética no se restringen tan solo a inculcar o trasmitir ciertas ideas, conceptos u opiniones 
relativas a lo que significa ser ciudadano, ni se limitan a la acumulación de información y/o al perfeccionamiento de conocimientos sobre asuntos de gobierno, la organización electoral y los derechos y obligaciones contenidos en las leyes y/o los deberes como mexicanos, sino que se refieren al desarrollo práctico-moral de actitudes y disposiciones fundamentales para regular los comportamientos de manera duradera, a partir de la desestabilización del sistema disposicional completo del sujeto (p. 31).

La deliberación y la comprensión crítica constituyen dos elementos axiales en la gestión pedagógica de los saberes a fin de promover aprendizajes de tipo práctico-moral en la formación cívica y ética, en el sentido planteado anteriormente por Yurén. Ellos involucran otros modos de entender las formas de regular los procesos de transmisión social en la escuela, que propician un margen de mayor apertura para el desarrollo del juicio crítico en los estudiantes dentro de las prácticas formativas escolares, distanciándose de la inculcación y el adoctrinamiento.

Así lo plantea Yurén (2005, p. 24) cuando subraya el carácter distintivo que adquieren los modos de adquisición de los saberes cuando se trata de aprender a ser y convivir, frente a los saberes teóricos y procedimentales: "mientras que estos últimos son transmisibles, los primeros no se pueden transmitir y solo se adquieren por la experiencia y el ejercicio. Se trata de saberes para la acción, que genéricamente pueden ser llamados saberes práxicos".

A diferencia de la palabra inculcar, que viene del latín (inculcāre) y significa apretar con fuerza algo contra otra cosa, o repetir muchas veces, con empeño y ahínco, una idea con el ánimo de infundirla en alguien, la deliberación es la capacidad para dilucidar situaciones controvertidas, examinar atentamente el pro y el contra de una elección, antes de tomarla y realizarla, y decidir y/o resolver una cosa después de un cuidadoso análisis.

La deliberación ocupa el lugar central en una formación cívica y ética que propicia la autonomía, pues desarrolla la facultad que tiene cada ser humano para analizar, comparar, contrastar ideas y establecer sus relaciones, lo que le permite decidir y hacerse cargo de tomar sus propias opciones y asumir la responsabilidad, en lugar de depender de lo que le digan que tiene que hacer.

Sin embargo, para saber elegir no basta con aprender los procedimientos de la deliberación. Hace falta el ejercicio de la comprensión crítica, que se desarrolla cuando podemos dilucidar y ubicar los problemas, reflexionar sobre sus causas y resolverlos. Vista como la capacidad de:

Analizar la información proveniente de diversas fuentes con el objeto de configurar su propia postura; la capacidad de identificar factores causales de un problema, así como los diversos elementos asociados a una problemática para anticipar consecuencias de sus actos y decisiones (Conde, 2004, p. 33).

Tal como lo plantea Conde, desde la comprensión crítica es posible incorporar la pregunta dentro de los procesos formativos; asumir una postura desde la cual nos atrevamos a preguntar cosas que tal vez nunca antes habíamos pensado; nos permite recuperar la posibilidad de imaginar que las cosas pueden ser de otra manera, capacidad que perdemos cuando asumimos como natural algo que a fuerza de la costumbre se vuelve normal y dejamos de cuestionar que pueda ser de otra manera, convirtiéndose así en la piedra axial para la configuración de una ciudadanía con agencia, que participa en la construcción del orden social.

Ahora bien, vistos como desafíos en la práctica docente, la deliberación y la comprensión crítica se convierten en los ejes de un nuevo modo de desarrollar los procesos de enseñanza y de aprendizaje, que convocan a los maestros en la configuración de nuevos roles profesionales que interpelan su identidad, al proponerles otras formas de reconocimiento como enseñantes.

En cuanto dinámica histórico-social, consideramos que la identidad docente se configura a través de un complejo proceso en el que se involucran significaciones sociales en torno a la docencia manifestadas en diversas tradiciones, junto con afectos $\mathrm{y}$ deseos que se producen en las trayectorias individuales y colectivas que se construyen en el ámbito 
social e institucional, por lo que su cambio supone una gran complejidad. En este sentido, el proceso de formación de significados solo se puede entender en la compleja red de factores que condicionan las maneras en que los maestros interpretan sus experiencias dentro de los concretos sistemas y estructuras en que viven.

En este sentido, si asumimos con Foucault (2003, pp. 7-8) que los procesos de identificación docente se construyen articulados con un sistema de reglas y restricciones que se producen al interior de la cultura escolar, en la correlación entre campos de saber, tipos de normatividad y formas de subjetividad, veremos la importancia de analizar la forma como significan la experiencia con el nuevo programa, suponiendo que todo proceso de construcción de significados se encuentra situacionalmente condicionado, y para entender su valor, sus efectos y sus implicaciones, es clave identificar las posiciones y marcos de referencia desde los cuales se elaboran sus interpretaciones y formas de intervención tal como plantea Pérez Gómez (1998, p. 67).

\section{El análisis: sobre la imposibilidad de pensar reflexivamente la realidad para la deliberación y la comprensión crítica}

En palabras de Yurén (2003), podemos decir que lo que se manifiesta al reconstruir las dificultades que manifiestan los maestros para manejar la nueva racionalidad curricular en el campo de la formación cívica y ética es la prevalencia de una cultura de la instrucción que, articulada a un modo de comprender los saberes escolares, impide la introducción de otros modos de entender la formación, articulados a lo que podríamos llamar una cultura de la formación.

Mientras que en la cultura de la formación el eje está centrado en la experiencia y en la lógica de la acción en el sentido planteado por autores como Dewey (1939) y Perrenaud (2002) -pues lo que interesa es que los alumnos desarrollen experiencias que se conviertan en una oportunidad para favorecer el desarrollo de lo que Puig (2003) refiere como prácticas morales ${ }^{5}$, al promover procesos de reestructuración de saberes, a fin de que lo que se aprende se vincule con las problemáticas que viven los sujetos en sus contextos de vida, poniendo en el centro sus propias necesidades e intereses, como condición para organizar a los contenidos educativos a fin de desarrollar aprendizajes significativos-; en la perspectiva de la cultura de la instrucción, la lógica curricular que prevalece es la enseñanza a pie juntillas de saberes organizados de manera secuencial en el currículo, donde lo que interesa es ver los temas del programa, a partir de una lógica de avance programático en la que no importa que la enseñanza produzca aprendizaje, cuando se privilegia la adquisición de dichos saberes aunque resulten poco pertinentes para el sujeto que aprende.

A partir de la reconstrucción analítica realizada, podemos decir que uno de los principales problemas a los que se enfrentan los docentes cuando se ponen en contacto con el nuevo enfoque en la formación cívica y ética es su dificultad para comprender la nueva lógica curricular que los estructura, cuando ellos significan la experiencia formativa, a partir de los principios de una cultura de la instrucción que se contrapone de tajo con los principios que sostendrían -por lo menos en términos declarativos- a los nuevos programas de formación cívica y ética; lo que hace surgir en ellos una demanda de formación dejada de lado por el afán instrumental. Así, se manifiesta en el siguiente fragmento que -aunque extenso- consideramos pertinente reproducir en su totalidad puesto que nos aclara la percepción que tienen los maestros con respecto a sus propias necesidades de actualización:

Yo veo muy difícil este planteamiento, porque ahorita todos estamos enfrentando los cambios, pero aparte estos cambios no es como en años anteriores que hay medio uno le entendía a los libros. Ahora no, ahora a los libros el maestro les tienes que buscar el sentido. Yo no sé si el objetivo

5 Para Puig (2003), las prácticas morales median entre la acción del sujeto y las pautas de cada tradición, y es por ello que constituyen un espacio privilegiado de la relación entre sujeto y entorno, así como un medio indispensable de aprendizaje moral. 
es orillar a que busquemos nuevas metodologías, que investiguemos más, o planeemos más nuestras actividades, pero eso no va a poder resultar si el maestro no tiene una preparación y una capacitación profesional, que no sea solo irse a los cursos de carrera magisterial donde hasta este momento -después de un año de estar yendo- no se les ha dicho cómo elaborar una planeación. Hasta este momento, en el curso se han ido por todo lo teórico y nadie ha sabido cómo elaborar una planeación, tratando de vincular todas las asignaturas, ¿no? Yo en la tarde estuve en una escuela piloto y fue mucha reflexión con los compañeros, porque había muchos compañeros que sí manejaban muchos elementos a nivel teórico, metodológico, y ellos sí lograron identificar esta parte de que la RIEB, realmente no tiene una coherencia, que parece que hicieron todo así parcharon, ¿no? Parcharon nada más, que incluso así como que copiaron y pegaron, copiaron y pegaron textos de algún lado... propuestas, en fin, y ellos comentaban lo triste que era dejar sobre todo los libros de primero y la falta de coherencia tan fuerte entre los libros donde hay que buscar todo, donde hay que planear todo, donde hay que buscar. Incluso ahora decían los compañeros, buscar hasta libros de otras editoriales para poder enriquecer el trabajo, porque realmente los libros se quedan cortos, ¿no? Es investigue esto, y si se acuerdan ustedes de tal contenido que vimos en tal, y si el niño no tiene contenido pues ya no lo pudo abordar, ¿no? El tema, y este yo creo que sí es bastante difícil abordarlo así. Ese es por un lado, yo creo que no hay metodología, y que el maestro no está lo suficientemente capacitado eh, y no se puede aventar al compañero así. Yo creo que tendría que haber una capacitación profesional realmente, y la otra parte es que se reduzcan las exigencias a nivel administrativo, pues son muchísimas eh. Entonces que el compañero se va entre exigencias, por ejemplo, que resultan así de pronto, ya en la familia que tenemos que hacer actividades afuera sobre el día de la familia, no pues que sobre la alimentación y que la supervisión pide en ese momento una actividad sobre eso o sobre ciencias, ¿no? Y algo se tiene que hacer sobre ciencias. Entonces, eso también orilla a que el compañero no lleve a la planeación, porque son actividades que en el momento se le solicitan. Eso, más todos los otros proyectos que se les ocurren (docente 7).

Tal como plantea la maestra, el nuevo modelo de intervención en la formación cívica y ética sugiere otro modo de asumir y de relacionarse con la naturaleza de su trabajo, al enfatizar que éste ha de ser asumido como una actividad reflexiva que demanda la toma de decisiones de manera autónoma y creativa. Lo anterior implica el desarrollo comprometido de acciones de formación que favorezcan que los docentes se hagan cargo de conducir su propia tarea de enseñanza en un marco de respeto a sus decisiones, al considerarlos interlocutores válidos en el debate acerca de las múltiples posiciones existentes en el entramado del discurso pedagógico que hoy día obturan la posibilidad del cambio, en la medida en que no se reconocen y mucho menos son escuchadas en el diálogo público que sobre los destinos de la escuela tendríamos que impulsar, a fin de que la reforma pueda llegar a ser algo más que una simulación de los que se quedan en la escuela, cuando la mirada vigilante de la autoridad cambia su foco de atención.

Al continuar en el análisis del discurso de los maestros, a fin de profundizar en la identificación de algunos de los factores que explicaban la permanencia de la cultura de la instrucción, más allá de la dimensión técnico-didáctica a que se han hecho referencia en el apartado anterior, llamaron la atención sus comentarios en relación con los alcances del trabajo educativo a fin de comprender la realidad.

Aun cuando en términos declarativos los maestros se pronuncian por la necesidad de propiciar una formación más orientada al desarrollo de aprendizajes significativos, ligados a la vida de los niños, ellos se cuestionan sobre la pertinencia formativa de hablar de determinadas cosas, de las cosas que quieren saber los niños, tal como lo manifiesta una docente en el siguiente fragmento:

Los temas de cívica y ética tratan de cosas de las que los niños quieren saber, pues ellos se enteran 
de muchas cosas que ni siquiera nos imaginamos. Se enteran en La rosa de Guadalupe o es que maestra pasó en Lo que callamos las mujeres (telenovelas mexicanas), y ya todos empiezan a comentar las cosas. Realmente ahí yo me he dado cuenta de que ¡no! Estos niños requieren otro tipo de ejercicios para que analicen y reflexionen lo que viven. Aunque eso, siendo honestos, la verdad no nos gusta, porque es más trabajo para nosotros, porque entonces debes de investigar para saber qué decirles. A veces los niños te hacen preguntas que tú dices ¡ay! ¿Cómo le voy a contestar? Por ejemplo, el otro día un niño que me dice: pero es que todos quieren ser presidentes para robarle al país, ¿verdad, maestra? Entonces, tú te quedas... para mí estos pocos años que llevo de maestra han sido un ejercicio para mí, pues yo pensaba que los niños no eran personas de verdad, y ahora me doy cuenta de que los niños son reales, son personas que ven, realmente ya no los duermes con que sí mira todo está bien bonito, ¡no! Tengo niños de tercer año que se van solitos a su casa y casi viven sin nadie que los ayude. Entonces eso es lo que está pasando, chicos reales y hay que darles conocimientos reales. Yo sé que también no te debes de olvidar de lo que ellos sí están viviendo. Pero de todas formas yo me pregunto: ¿cuáles deben de ser estos conocimientos? ¿Se trata de llenarlos de los problemas que vivimos, o la escuela debe de convencerlos sobre cómo deberían ser las cosas en realidad? (docente 5).

Tal como se plantea en el fragmento anterior, aunque se reconoce la importancia de introducir el análisis de las vivencias de los niños dentro de los muros de las aulas, en los hechos encontramos que los maestros se resisten a aceptar esa nueva forma de trabajo debido a que ella les implica invertir un mayor tiempo de dedicación en los procesos de planeación, pues deben investigar para saber que decirles, además de que se pone a prueba su capacidad para conducir y organizar una situación formativa con otras características.

Ahora bien, aunque encontramos que los elementos anotados anteriormente resultan significativos para explicar la renuencia de los maestros para introducir otro modo de trabajar los conteni- dos educativos, resulta necesario detenerse en otro aspecto que comenta la maestra cuando expresa su cuestionamiento hacia el final del texto que hemos transcrito: ¿se trata de llenarlos de los problemas que vivimos o la escuela debe de convencerlos sobre cómo deberían ser las cosas en realidad? La pregunta que se hace la maestra hacia el final del texto sintetiza con claridad la disyuntiva a la que se enfrentan los maestros hoy día, cuando se presenta la oposición entre el mandato de la escuela al formular un discurso moralizante para hablar sobre cómo debe ser ese mundo ideal, frente a la exigencia de hablar de las problemáticas de la realidad tal como son. En la formulación del cuestionamiento, pareciera que lo que se manifiesta son indicios que muestran la resistencia de parte de los maestros para tratar determinados temas que muestran el lado oscuro de nuestra convivencia, o que simplemente provoquen controversia en un mundo escolar construido falsamente sobre una creencia de neutralidad valorativa.

A fin de comprender a mayor profundidad la complejidad del argumento esbozado por la maestra, transcribimos los siguientes fragmentos que, aunque extensos, resultan relevantes para identificar la naturaleza de la crítica que realizan los docentes al modo de tratamiento de los contenidos educativos en los nuevos programas del PIFCYE:

- Estábamos viendo el artículo de la ley del trabajo, y les digo, ¿ya vieron cuántas horas debe de trabajar un trabajador? Ocho horas. Y muchos empezaron a hacer sus cuentas y allí vino el problema: “¡oiga, maestra, mi mamá trabaja tantas! ¿Por qué trabaja tanto si eso no está en la ley? Oiga, entonces mi mamá trabaja horas extras, pero no se las pagan”. Y, entonces, te das cuenta y tú dices ¡ups! ¡Ah! y las embarazadas tienen derecho especial, ¡no! Pero mi tía estaba embarazada e iba a trabajar y todavía trabaja. Entonces, a veces ellos se dan cuenta realmente de la política que hay en el país. Otro día, también un niño curiosamente me pregunta: ¿quién es nuestro presidente? Y yo le respondí que era Felipe Calderón. Pero, entonces él me dijo: pero Felipe Calderón le 
robó los votos a Andrés Manuel. O sea, que los niños ya están más enterados, están más entrometidos (docente 5).

- El problema del libro es que despierta muchas opiniones. Por ejemplo, te despierta muchas opiniones en la ley del trabajo, en el patrimonio cultural. Me decían: "y si es patrimonio de la cultura, ¿es mío?” Les digo, bueno, hay que cuidarlo. ¡Pero es que nunca nos dejan pasar! ¿Cuándo se deja pasar? No. Por ejemplo, la séptima maravilla Chichen Itzá, no ya hasta una de las maravillas, y me dicen los niños, "pero maestra, eso es de nosotros pero no lo ocupamos, vamos y no nos dejan pasar". Entonces, sí despierta mucho la curiosidad del niño. Y dice bueno: todo lo que me estás diciendo aquí maestra, que es mío, que es mi nación que es mi país, por qué, por qué sigue habiendo mucha gente pobre, dice, por qué en el metro sigue pasando, sigue pasando. No, un libro más apegado a la realidad pienso yo, porque mire, aquí está lo del patrimonio cultural (señalando la página), ¿a poco eso es mío? Pero patrimonio es nada más lo que me deje mi papá, ¿no?, sí, sí, es lo que te va a dejar tu papá y este, pero tú lo tienes que cuidar también como te cuidó de chiquita. No pues tú también ya le tienes que ir poniendo. ¡Ah maestra! Pero mi papá dice que si no pagamos algo nos quitan la casa, no entonces tú ya no sabes si es el predial, o si es la renta, sí, realmente este libro tiene muchos problemas (docente 5).

- Yo no sé si es bueno decirle a los niños todas estas cosas. Yo digo que al decirle al niño no que tus papás te tienen que cuidar, y que tus papás tienen que darte todo lo necesario cuando tenemos niños que no es así. Yo creo que sí les crea conflicto muy fuerte, porque a veces yo creo que, sin querer, desarrollamos ciertas condiciones en los niños, por ejemplo, de depresión, ¿no? Al manejar estas situaciones así, en lugar de manejar la realidad como es, así como es. Ayer lo veíamos con una chiquita que la maestra la sorprendió con un cúter, pues se quería cortar en las venas, y cuando empiezan a hablar de esta situación pues, y si estaba así que se iba a cortar entonces ya explorando la situación y hablando con los niños, porque ahorita le decían sí, sí córtatelas, no córtatelas y ya no era la primera vez, entonces este... hablando con ellos y así sí usted entra a los grupos y empieza a desatar tantito, no es una serie de problemáticas terribles que nada tienen que ver con lo que estamos manejando, en lugar de manejar: a ver, se está dando esto, cómo lo podemos resolver o cómo lo podemos enfrentar, o sea, dar una explicación de la realidad (docente 7).

- Los libros hablan de cosas ideales, pero que no están apegadas a la realidad, que no se adaptan a ella. Los niños necesitan aprender cosas más apegadas a lo que estamos viviendo, a lo que nosotros como maestros vivimos en el aula, porque si no se frustran. Por ejemplo, con el tema del agua a mí me dicen en el programa y los libros que dialogue sobre el uso del agua, ¿no? Y entonces estamos con que: ¡cuidemos el agua! ¡Cuidemos el agua! Pero de qué sirve que les enseñe eso si los niños me dicen; oye, maestra, pero yo ya cuidé el agua y mi mamá también cuida la que usamos para los trastes que usamos y la echas después para lavar el patio, pero ¿qué más puedo hacer?, ¿no? O sea, prácticamente dice: ¿qué más quieres que haga? Si yo lo llevo a cabo, pero de todos modos no hay agua en mi colonia, y entonces se frustran. ¡Oye, cuida el agua! Maestra pues no hay agua, muchos viven en Iztapalapa, pero me dicen: maestra, es que allá no hay agua, entonces llenamos botes grandes, mi mamá dice que con poquita porque no hay. Luego dicen: maestra, en mi casa hay una fuga, y ¿ya la reportaron? Ya, dice, ya nos pusimos de acuerdo con los vecinos, pero no van (docente 5).

- Lo que tratan los libros está muy fuera de la realidad, es que nada de lo que se plasma en los libros tiene que ver con lo que estamos viviendo. Por un lado, si le estamos diciendo 
al niño que la justicia, la paz, el diálogo, pero en la vida real eso no existe, y entonces pues les creamos una contradicción muy grande. No vayamos más lejos, en la escuela no hay justicia ni equidad porque en la misma escuela el maestro dice "así debe ser". Pero no hay coherencia con lo que se les está enseñando, porque es todo lo contrario (docente 7).

A partir de los fragmentos que compartimos anteriormente, se expone una lógica de argumentación compleja, la cual muestra los matices que adquieren las críticas que los maestros realizan en torno a la propuesta que se presenta dentro del PIFCYE para trabajar los contenidos educativos.

Aunque entreverando diversas aristas en su discurso, resultó significativa la coincidencia encontrada en la mayoría de ellos sobre las razones para descalificar el perfil que adquiere el contenido educativo de la propuesta. Por un lado, diversos maestros señalan el inconveniente de problematizar la realidad, cuando dicha acción puede resultar conflictiva, debido a que cuestiona el orden de cosas vigente, por lo que consideran que lo mejor es manejar la realidad como es, así como es, aunque dicha decisión venga acompañada de la renuncia de problematizar el orden de cosas tal cual es dentro del ejercicio de la formación eminentemente escolar, excluyendo así la posibilidad de imaginarizar futuros distintos, como lo plantea Carlos Cullen (2003).

En este orden discursivo, la posibilidad de pensar sobre la realidad se elimina en aras de la transmisión de un discurso ideal prescriptivo que va a la par de la reproducción cultural del orden de cosas como es y que, por tanto, no puede ser de otra manera. Tal como se desprende de los comentarios transcritos, pareciera que uno de los problemas existentes con el nuevo programa y el libro de texto es que legitiman la posibilidad de hablar de temas que hasta hace poco eran excluidos en la escuela. Sin embargo, la posibilidad de posicionar temas otrora silenciados, como el de la discriminación, o traer las situaciones particulares que viven los niños, al entrar al terreno de su vida con toda su crudeza, obliga a los maestros a hablar sobre la realidad, convirtiéndose en interlocutores de los niños, a fin de buscar construir soluciones más allá de los límites que establece la mirada idílica que prescribe cómo debe ser el mundo. Se trata del lugar discursivo donde los maestros se sienten menos amenazados al estar más seguros y cómodos.

Ya sea porque les implica dejar de lado el ideal, a fin de pensar en lo que verdaderamente sucede, o porque resulta impensable introducir los valores controvertidos en el ámbito escolar, lo que es cierto es que la reticencia para hablar sobre la realidad, desde una perspectiva crítica se convierte en un obstáculo importante para introducir modificaciones en la forma de tratamiento de los contenidos educativos, a fin de transitar de una cultura de la instrucción a otra centrada en la formación.

Hacer realidad este enfoque en la formación cívica y ética resulta complejo, tal como hemos visto hasta ahora, debido a que se hace necesario que la escuela se torne más permeable a lo que sucede en la comunidad donde está inscrita, de modo que maestros y alumnos no se queden solo en el aprendizaje instrumental del diálogo, mediante la deliberación en torno a asuntos triviales y supuestamente neutrales, sino que se involucren en el debate de necesidades reales y sustanciales para arribar a soluciones factibles, y lo anterior requiere de la redefinición de la función docente.

A través de la comprensión crítica y la deliberación, se favorece que los niños y las niñas puedan desarrollar el juicio ético como capacidad fundamental para analizar las distintas realidades, a fin de tomar una posición frente a ellas; sin embargo, pareciera que para los maestros resulta difícil asumir ese principio de la intervención educativa, pues implica romper con el hermetismo -recuperando una categoría etnográfica introducida por un maestro en su discurso- que impide la conexión de lo que se enseña y aprende en la escuela con las problemáticas de la realidad -la vida-, tal como se expresa en el siguiente fragmento:

Tendría que abordarse la parte del alcoholismo, la drogadicción y la violencia intrafamiliar de manera más fuerte, porque yo creo que en la 
escuela nos quedamos cortos, y somos muy cerrados y herméticos y no queremos hablar de nada de eso. No puedes prohibir que se hable de todo lo que viven, siempre es mejor reconocer que existe, porque lo importante no es taparlo, sino ver cómo lo enfrentamos. No hay que tener miedo, no se trata de detener, sino de tratar de utilizar algo. Sin embargo, la mayoría de los maestros no ven cómo se puede utilizar y buscar un beneficio para nosotros, sino que solo se trata de detener, es como que quieren que la escuela se cierre herméticamente para que no se contamine con nada (docente 7 ).

Esta estrategia de silenciamiento se opone al desarrollo de algunas de las premisas básicas del programa, articuladas a la necesidad de promover la comprensión crítica y la deliberación como ejes angulares en el desarrollo del juicio crítico. Partiendo del falso argumento según el cual si algo no se nombra no existe, la estrategia del hermetismo acalla la realidad y, con ello, la posibilidad del debate de perspectivas. Así, resulta difícil pensar la discusión de los valores controvertidos, cuando se trata de transmitir la verdad sobre algo, aunque ello implique excluir cualquier otra visión o perspectiva que la contradiga. Con ello, la polifonía -que produce el ejercicio público de las diversas ideas y puntos de vista sobre las cosas- es excluida del ámbito escolar, cuando dicha práctica es valorada de manera negativa, pues se considera que puede ser nociva para el cumplimiento de los objetivos formativos. Esto se manifiesta en el siguiente fragmento, donde un maestro se refiere a la imposibilidad de hablar y pensar sobre la realidad como objeto central de la formación:

Yo creo que los maestros no podemos relacionar los contenidos de las distintas materias, porque no estamos de acuerdo en hablar de ciertas cosas, pues como digo somos muy herméticos. ¡Esa es la verdad! La Cívica y Ética, yo no lo veo mucho como asignatura única, esto de "vamos a ver Cívica y Ética” en la hora de Cívica y Ética, a mí no se me da. No lo veo separado, sino siempre la relaciono dentro del trabajo con los niños, pero solo si estoy de acuerdo con los derechos, por ejemplo, o con hablar de los cambios que tienen los niños en su cuerpo o con la sexualidad. Pero si yo no estoy de acuerdo, por ejemplo, en lo de los derechos, ¿cómo voy a hacerlo? Claro que no: "bueno muchachos vamos a leer qué pasa con nuestro cuerpo, no es que dicen que los derechos del niño hay respetarlos y no sé qué, y que también hay que tener cuidado porque uno va a cambiar, bueno vámonos a Naturales, ¿qué dice en Naturales? No que vamos a tener cambio físicos y una niña, nosotras algunas ya tuvimos cambios maestro, porque antes, a sus palabras, antes éramos planitas y ahora ya no, le digo ah bueno y los hombres, no maestro es que a mí me están creciendo vellos en el pecho, y otros ay parece chango, le digo no, es que a todos nos va a pasar, ah bueno, y bueno (docente 1).

Frente a la necesidad de unir, articular, poner en contacto qué nos plantea el nuevo programa, a través del principio del hermetismo se fortalece la fijación de oposiciones dicotómicas. Esto hace más altos los muros que dividen la frontera entre la escuela y la vida a fin de cumplir sus objetivos formativos y evitar que entren las cosas malas para así poder aprender cosas buenas, tal como nos comentó otra maestra: "creo que aquí estamos en un lugar de enseñanza, y si aquí vienes a aprender cosas buenas, no traigas cosas malas" (docente 3 ). Es a partir de este mecanismo que, como lo plantea Fattore (2007, p. 18), se consuma:

[...] El carácter de aislamiento que asume la pedagogía tradicional que da cuenta de la necesaria traducción que aquel que ingresa al territorio escolar debía realizar, este adaptarse a un espacio que siempre resultaba extranjero. Un corte entre escuela y sociedad que se manifiesta en la cultura escolar.

El principio del hermetismo, existente en la escuela, se convierte en una regla a partir de la cual se realiza la selección y distribución de los saberes legítimos en el plano formativo, dejando de lado la posibilidad de hablar de temas espinosos o controversiales al establecer una prohibición tajante para reflexionar sobre aquellos aspectos relacionados con problemáticas significativas en la vida de los alumnos, debido a que, como lo plantea el maestro, en la escuela no se está de acuerdo en hablar de ciertas cosas. Es así que dicho principio se con- 
vierte en organizador de las prácticas, impidiendo la posibilidad de pensar lo impensado en el sentido planteado por Bernstein (1998). De ese modo, a contracorriente de los nuevos discursos que enfatizan la necesidad de promover la deliberación debido a sus efectos formativos, en términos generales más allá de la conformación del sujeto ético, el principio del hermetismo expulsa el debate de perspectivas, $y$ con ello la posibilidad de la deliberación en la medida en que lo que interesa es la preservación de un orden de cosas apegado a lo existente.

Dicho principio convierte la escuela en un terreno aparte, ficcional, que enmascara la realidad, que esconde, que oculta, en un lugar donde habita una sola verdad y donde no hay cabida para diversas perspectivas, que defiende su autoridad pedagógica para decidir que sí y que no se puede hablar en su interior, asumiéndose como ley, que impide la inclusión de cualquier otro discurso alterno, privatizando así un espacio público que por naturaleza habría de dar lugar a la multiplicidad de voces que tiñen de múltiples colores a nuestra sociedad.

En este mundo donde se multiplican los caminos, donde el cambio y la incertidumbre constituyen los signos de nuestra época, resulta imprescindible poner el acento en el impulso de procesos formativos que contribuyan a problematizar la realidad a fin de comprenderla y propiciar su transformación, construyendo así la posibilidad de imaginar mundos distintos; sin embargo, pareciera que este afán de no permitir el análisis de la realidad tuviera como objetivo o finalidad eliminar la posibilidad de que la escuela se convierta en espacio para pensar lo impensado e imaginar nuevas realidades a partir de las cuales construir futuros distintos.

Ahora bien, en esa intención de silenciar la realidad no solo participan los maestros, sino que también contribuyen los padres, pues ellos juegan un papel fundamental en la construcción del cerco que habrá de impedir que se nombre la realidad, a fin de posibilitar el desarrollo de su comprensión crítica. Así participan los padres en dicho esfuerzo:

Lo que veo es que son madres de familia interesadas, pero acostumbradas como a un estilo más... hermético: porque aquí tú no vas a hacer lo que tú quieras, va a ser lo que yo te diga. Y ha pasado con algunos de mis muchachos: ¡oiga, señora! Es que yo les dejé que investigaran, sí maestro, pero cómo lo iba hacer no estaba bien, a mí me enseñaron que se hace de esta manera. Es por eso que, además de los maestros, tenemos que lidiar también con los problemas de afuera para traerlos a la escuela (docente 1).

Es así que la complejidad del reto de modificar las prácticas formativas se hace evidente, cuando se comprende que, más allá de la simple introducción de ciertos lineamientos didácticos novedosos, se trata de cambiar un modo de ser y de entender el papel de la formación, de parte no solo de la escuela sino también de la comunidad, tanto así que el mandato no deja espacio para el equívoco: las cosas se hacen de esta manera, porque así deben ser.

La resistencia de los padres de familia a los nuevos enfoques del programa se hace evidente en relación con diversos aspectos que van desde el uso de determinadas fuentes como la Internet hasta la posibilidad de hablar de temas que ellos consideran nocivos para los niños. Es así que ellos, junto con los maestros, contribuyen al cierre y la imposibilidad de propiciar la innovación, en la medida en que, además de la resistencia que hemos identificado entre los maestros, resulta difícil la negociación y mucho menos el convencimiento de los padres de familia sobre la valía de los nuevos recursos, estrategias y formas de enseñanza.

Al seguir profundizando en el análisis, encontramos que la negativa para problematizar la realidad pudiera estar relacionada con el hecho de que los maestros consideran que la función de la escuela, en el campo de la formación cívica y ética, se relaciona con la adaptación a la moral social y a los valores vigentes, más que a la posibilidad de estar abiertos a la construcción cultural de nuevos valores acordes con las nuevas condiciones en que vivimos.

Lo fundamental es que los niños se adapten, porque si no solo vamos a crear niños desadaptados a los que les enseñemos unas cosas y resulta que eso no lo viven allá afuera. Lo que yo me pregunto es hasta dónde vamos a llegar, o qué pretendemos. Necesitamos fijarnos una meta, porque yo creo que hay cosas de este nuevo programa que no 
nos van a beneficiar mucho. Por ejemplo, hemos visto que se ha aplicado muy bien lo de justicia, legalidad, y nosotros mismos en nuestra casa no lo practicamos con nuestros hijos, con nuestros papás (docente 8).

Lo anterior implica, a decir de Furlan (2005, p. 1101), que lejos de asumir una posición de distanciamiento crítico con respecto a la realidad, lo que interesa es la adaptación a la realidad tal cual es, manifestando con ello la correspondencia de ciertos comportamientos instrumentales docentes.

Al situar el comportamiento didáctico fundamentalmente en el plano de la racionalidad instrumental, la actitud frente a lo real es tomarlo como viene, mostrando capacidad para adaptarse a las demandas que esa realidad genere. El propósito de criticar la realidad es algo totalmente ajeno a la racionalidad instrumental.

\section{A modo de reflexión final}

Haber analizado la valoración que los maestros realizan en torno al Programa Integral de Formación Cívica y Ética, a fin de comprender los caminos por los que transitan actualmente los procesos de significación de la propuesta en el ámbito de sus prácticas formativas, nos ha permitido realizar un primer acercamiento de tipo exploratorio a fin de identificar algunas de las tensiones, dilemas y paradojas que se presentan en el proceso de su desarrollo en el ámbito de la escuela primaria como espacio localizado de formación de ciudadanía.

A partir del diálogo con los maestros y maestras, y con la revisión de diversos referentes, fue posible encontrar sentido a un proceso que a primera vista aparece caótico, al dejar ver solo la simulación y resistencia, cuando lo que prima en los supuestos afanes reformadores es la estrategia del innovacionismo burocrático.

Entre los hallazgos más significativos, derivados de este acercamiento de investigación, se encuentra la identificación de algunas de las tensiones que de manera significativa obturan la posibilidad de introducir los nuevos referentes para pensar la formación cívica y ética desde una perspectiva democrática.
Por un lado, el acercamiento realizado nos dejó ver que la posibilidad de articulación del programa, en el plano de las prácticas, se encuentra condicionado por la dificultad existente para comprender la lógica de la transversalidad en la organización de los contenidos curriculares. Esa dificultad, si bien se origina en la falta de familiaridad de los maestros con los esquemas metodológicos de organización curricular de tipo integrado, evidencia la presencia de otro tipo de factores relacionados con la dificultad para pensar la realidad, a fin de aspirar a su comprensión crítica a través de la deliberación. Asimismo, la reconstrucción realizada acerca de los procesos de articulación del programa nos permitió identificar la contraposición existente entre las finalidades de la formación cívica en el ámbito escolar con aquella que en términos declarativos se busca impulsar a través del PIFCYE. En la medida en que lo que interesa a los maestros es la enseñanza de hábitos es que se reproduce un tipo de formación cívica y ética que impide la construcción de autonomía en los alumnos en aras de promover la modelización de comportamientos según cómo deben ser.

A partir de la reconstrucción realizada, vemos la cadena de significación que impide que la escuela se convierta en un espacio para pensar la realidad como condición básica para favorecer el desarrollo de la deliberación y la comprensión crítica. Mientras ello no se convierta en foco de atención, difícilmente podremos ir más allá del sabido método centrado en el adoctrinamiento, y la inculcación a partir de la cual, más que conformar a un sujeto ciudadano crítico y capaz de intervenir responsablemente en la construcción del orden, reproducirá modelos a través de la obediencia.

Las dificultades encontradas evidencian la importancia que juega la dimensión ético-política en los procesos de innovación de las prácticas, razón por la cual resulta conveniente no dejarse llevar por el protagonismo que adquiere el discurso técnicodidáctico cuando se reconoce que la identidad de los maestros como enseñantes desempeña un papel importante al momento en que los docentes entran en contacto con las nuevas propuestas generando un punto de vista sobre ella. 


\section{Referencias bibliográficas}

Bernstein, B. (1998). Pedagogía, control simbólico e identidad. Madrid: Morata.

Conde, S. (2004). Educar para la democracia, $2^{\circ}$ de preescolar. Fichero de actividades, México: IFE.

Cullen, C. (2003). La ciudadanía como problema educativo. Ponencia presentada en el evento de presentación de resultados de la Consulta Infantil y Juvenil 2003. Instituto Federal Electoral. Mecanograma.

De Certau, M. (1996). La invención de lo cotidiano. Antes de hacer. México: Universidad Iberoamericana.

Dewey, J. (1939). Experiencia y educación. Buenos Aires: Losada.

Fattore, N. (2007). "Apuntes sobre la forma escolar 'tradicional' y sus desplazamientos”. En R. Baquero, G. Diker y G. Frigerio (comp.), Las formas de lo escolar (pp. 13-32), Buenos Aires: Del Estante.

Foucault, M. (2003). Historia de la sexualidad 2. El uso de los placeres. México: Siglo XXI.

Fuentes Amaya, S. (2004). "Identidad profesional e identificación: Hacia una lectura desde lo discursivo y lo psíquico". En E. Remedí, (coord.), Instituciones educativas. Sujetos, historia e identidades (pp. 161-189). México: Plaza y Valdez.

Furlan, A. (2005). Entre las buenas intenciones y los acuerdos funcionales. El tema de la violencia en la formación inicial de profesores de secundaria en México. Revista Mexicana de Investigación Educativa, 27(10), 1083-1108.

Guevara Niebla, G. (2006). Democracia y educación. Dos notas críticas. Revista Mexicana de Investigación Educativa, 29(11), 639-653.

Gómez, P. (1998). Estudio para el diseño de la estrategia de un programa de educación cívica del Instituto Federal Electoral. México: CEE-IFE.

Pérez Gómez, A. (1998). Historia de una reforma educativa. Sevilla: Díada editora.

Perrenoud, P. (2002). Construir competencias en la escuela. Santiago de Chile: Dolmen.

Puig, J. (2003). Prácticas morales. Una aproximación a la educación moral. Barcelona: Paidós.

Rodríguez G., Gil, J. y García, E. (1999) Metodología de la investigación cualitativa. Málaga: Aljibe.

Taylor, S. y Bogdan, R. (1987). Introducción a los métodos cualitativos de investigación. Buenos Aires: Paidós.
SEBYN (2008). Programa Integral de Formación Cívica y Ética. México: Secretaría de Educación Pública.

Yurén, T. et al. (2003). La asignatura "Formación Cívica y Ética" en la secundaria general, técnica y telesecundaria. Su sentido y condiciones de desarrollo en el Estado de Morelos. México: Universidad Autónoma del Estado de Morelos. Documento de trabajo.

Yurén, T. (2005). "Ethos y autoformación en los dispositivos de formación de docentes”. En T. Yurén, C. Navia y C. Saenger (coord.), Ethos y autoformación del docente (pp. 19-45). Barcelona: Pomares.

Yurén, T. (2007). Eticidad y contingencia en la formación ciudadana. Revista Metapolítica, 53(11). 